\title{
Correction: Selective laser trabeculoplasty: past, present, and future
}

\section{A. $\operatorname{Garg}^{1} \cdot$ G. Gazzard ${ }^{1}$}

Published online: 23 October 2019

(c) The Royal College of Ophthalmologists 2019

\section{Correction to: Eye}

$$
\text { https://doi.org/10.1038/eye.2017.273 }
$$

Since the publication of the above article, the authors have noted an error with their affiliations associated with this article. The authors apologise for any inconvenience caused by this error. The correct affiliation for both authors is:

NIHR Biomedical Research Centre at Moorfields Eye Hospital NHS Foundation Trust and UCL Institute of Ophthalmology, London, United Kingdom
G. Gazzard

g.gazzard@nhs.net

1 NIHR Biomedical Research Centre at Moorfields Eye Hospital NHS Foundation Trust and UCL Institute of Ophthalmology, London, UK 